\title{
GÖDEL MEETS CARNAP: A PROTOTYPICAL DISCOURSE ON SCIENCE AND RELIGION ${ }^{1}$
}

\author{
Alfred Gierer \\ Max-Planck-Institute for Developmental Biology, Tübingen
}

\begin{abstract}
Modern science, based on the laws of physics, claims validity for all events in space and time. However, it also reveals its own limitations, such as the indeterminacy of quantum physics, the limits of decidability, and, presumably, limits of decodability of the mind-brain relationship. At the philosophical level, these intrinsic limitations allow for different interpretations of the relation between human cognition and the natural order. In particular, modern science may be logically consistent with religious as well as agnostic views of humans and the universe. These points are exemplified through the transcript of a discussion between Kurt Gödel and Rudolf Carnap that took place in 1940. Gödel, discoverer of mathematical undecidability, took a proreligious view; Carnap, one of the founders of analytical philosophy, an antireligious view. By the time of the discussion, Carnap had liberalized his ideas on theoretical concepts of science: he believed that observational terms do not suffice for an exhaustive definition of theoretical concepts. Then, responded Gödel, one should formulate a theory or metatheory that is consistent with scientific rationality, yet also encompasses theology. Carnap considered such theories unproductive. The controversy remained unresolved, but its emphasis shifted from rationality to wisdom, not only in the Gödel-Carnap discussion but also in our time.
\end{abstract}

The relation between religion and rational thought about nature has been ambivalent ever since the ancient Greek philosophers conceived explanations of nature in theoretical terms some twenty-five hundred years ago. Anaxogoras, Protagoras, and presumably others as well were exiled because their views were considered heretical. Yet, the Greek philosophers were inspired, not only by external information from cultural centres in Egypt, Persia and Babylonia, but also by a growing tendency within their own religious culture to personify general concepts, such as justice by the goddess Dike. In return, Greek philosophy has contributed much to the development and transformation of religious ideas, from Xenophanes' abstract monotheism onward. Greek rational notions made their impact again and again in more than 2,000 years to follow. For instance, Aristotelianism was first rejected, then incorporated and eventually vehemently defended by religious authorities in medieval

\footnotetext{
${ }^{1}$ This is an electronic version formated in TEX of the article A. Gierer (1997) "Gödel meets Carnap: A prototypical discourse on science and religion". Zygon 32, 207-217. Complete citation information for the final version of the paper, as published in the print edition of Zygon, is available on the Blackwell Synergy online delivery service, accessible via the journal's website at www.blackwell-synergy.com
} 
Europe. The earth was viewed as spherical, against biblical tradition. In the 12th century, Thierry of Chartres, accepting the biblical description of creation as more or less metaphorical, presented a much more scientific version of creation: God created the elements and the laws of nature (understood in Aristotelian terms), and then life developed by itself. It was medieval theologians, such as Albertus Magnus, who rediscovered the "book of nature" as God's revelation, complementary to the Bible. The founders of modern science- Galileo Galilei, Johannes Kepler and Isaac Newton - professed Christian beliefs by conviction, not opportunism. The clash between science and religion in the trial of Galileo Galilei was not free of contingencies, partially resulting from personality traits of the physicist and the Pope, but it led religious authorities to a level of discourse far below that achieved centuries earlier by liberal medieval theologians.

From the eighteenth century onward, clearly agnostic ideas spread widely, often in close association with scientific notions. Animals, if not human beings, were considered machines, the universe a clock, and God unnecessary for understanding ourselves and nature around us. These lines of thought were often considered to be intuitively supported by the advances of science. The basic laws of physics were extended to encompass more and more events in space and time, suggesting a "mechanistic", deterministic universe in which corpuscles moved according to the laws of motion and nothing else, thus devaluating immaterial concepts of God, soul, and free will. To many observers of the 19th century, the evidence showing the evolution of man from animal ancestors appeared as a final blow to traditional religion. For these reasons, around the turn of the twentieth century, many persons (and perhaps most intellectuals) thought that religion would eventually disappear in favour of a culture directed by scientific rationality, be this prediction expressed in a regretful, anxious, disinterested or triumphant mood.

The intellectual scene at the end of the twentieth century is different. The mainstream in the scientific community still avers that one can do better without religion than with, but the claim that science proves on logical grounds that religion is superfluous or unfounded is not so widespread as a century before and no longer standard opinion in the "hard sciences" such as physics and mathematics. Empirically, it is obvious that religion persists and is even increasing in many parts of the world. Therefore the prediction that religion will disappear or be reduced to negligible levels must be replaced by a much more likely scenario: coexistence of agnostic and religious thought in the long run.

In fact, the science of the twentieth century itself contributed to this fundamental insight by demonstrating its own intrinsic limitations. With the development of quantum physics, the challenge of understanding the domain of the invisibly small (down to atomic dimensions) led to an extension of the laws of mechanics to fully encompass the atom and the chemical bond, the structure of molecules and their interaction. This in turn was a precondition for molecular biology, which led to an understanding of the basic life-processes - reproduction, mutation, and metabolism - 
on a molecular, and thus a physical, basis. The fundamental laws of quantum physics apply to all events in space and time, yet the structure of the new physics revealed unexpected limitations and has taken an epistemologically revolutionary form. It asserts that it is not possible, in principle, to calculate all future events in atomic dimensions on the basis of data measurable at present; in cases in which events in small dimensions are enhanced to macroscopic scale, the future is incalculable in principle, not only in practice. This includes such processes as chromosomal recombination, which strongly affects the genetic constitution of future organisms, including human beings. Even more important from a philosophical point of view, the formal structure and meaning of quantum physics are such that the new physics is a theory, not of reality itself, but of possible knowledge of reality. There appears to be a deep relation between human cognition and the internal order of nature. The scope and limits of physics allow for different philosophical interpretations. One of them is theologically oriented - considering the creativity of the human mind in understanding nature as reflecting the creativity of its Creator.

An analogous example, in which the expansion of knowledge leads to determining and understanding the limits of knowledge, is mathematical decision theory. Up to the twenties, it was an ideal of mathematics to set up systems of axioms which would allow for a proof of their internal consistency, implying that no two lines of deductions could ever lead to contradictory statements. It was Gödel who found that this aim cannot be reached in principle. Formal logical systems sufficiently powerful to encompass general concepts as well as arithmetical manipulations do not allow a proof of their internal consistency by their own means. Like quantum indeterminacy, mathematical undecidability is also consistent with different philosophical interpretations. It appears that any formal thinking is based on intuitive presuppositions. This, in turn, may - but need not - suggest transcendental aspects of the human mind that cannot be exhausted by objective, formal analysis.

It appears that further limitations of objective science have to be envisaged with respect to the mind-brain relation. Mental states are directly accessible to us in consciousness. In addition, we know on theoretical, scientific grounds that mental states are related to brain states and that these, in turn, result from processes for which the laws of physics appear to be fully applicable. However, it does not follow that the mind-brain relation must be decodable by finite algorithmic procedures ${ }^{2}$. Analogies with Gödel-type theorems of mathematical undecidability suggest that limits of decodability are to be envisaged, in particular, in relation to self-referential operations of the human mind. If this is the case, a complete objective theory of the mind would not be possible; the concepts of physics would apply to the brain, but the features deducable by finite analysis would not exhaust all aspects of the human mind. Subjective experience could provide information that would not be accessible from physical data alone.

The relation between physical laws and the occurrence of life in the universe is another crucial problem that may not lend itself to a stringent scientific solution. Life 
could develop only because there are stars and planets have persisted over billions of years, because physics allows for organic chemistry based on the properties of the carbon atom, and because many other conditions are met, conditions by no means trivial; rather, they depend sensitively on the structure of the basic laws of physics, on the numerical values of the "constants of nature" therein, and on the initial and boundary conditions of the development of the universe, particularly with regard to its earlier stages. Is the universe habitable by chance, by design, or for some other reason? One of the conceivable explanations is the "design"-version of the "anthropic principle": it proposes that it is a law of nature - a kind of "meta-law" - saying that the structure and numerical constants of physical laws, as well as the initial conditions of the universe, are set in a way that permits life and mind to evolve materially in the course of development of the universe. One of the interpretations, in turn, is a religious one: The universe is created by God so as to allow for the evolution of life, including that of beings that are in God's image (in the cognitive, mental sense of the term) - human beings having comprehending and creative minds. This interpretation is not the only possible one, but it is logically fully consistent with the body of scientific knowledge that we accept.

All lines of thought - be they on quantum indeterminacy, mathematical undeciability, the limits of decodability of the brain-mind relationship, or the question of how and why the physical conditions of the universe allow for the evolution of life and mind - indicate that it is possible to interpret nature and the human mind in agnostic as well as in religious terms and that both types of interpretation are fully consistent with logical thinking and scientific facts.

In the nineteen-twenties, the same decade in which quantum physics was developed, a new line of philosophical thinking was conceived in Vienna by Rudolf Carnap and his friends in an attempt to reach a new stringency far beyond traditional philosophy. The key note of "analytical philosophy" was to restrict itself to scientific methods and to scientifically meaningful questions. In the long run, this effort did not reach all of the targets it set; it turned out that to find a scientific definition of meaningful would be difficult, and to discover a method of assessing methods would be impossible because this method would eventually have to assess itself. Further, analytical philosophy intrinsically tended to overrate formalization and, at the same time, to exclude some of the most interesting problems of philosophy from consideration just because they did not lend themselves to formalization. Nevertheless, some of the results appear to be of permanent, rather than transient, value. This applies particularly to the analysis of theoretical concepts within the framework of scientific theories.

Originally, Carnap and his friends had proclaimed that the new philosophy would do away with all fuzzy metaphysical notions. Such concepts as "God", "soul", and "ideal", were said not to contribute anything towards an understanding of the real world. Theoretical concepts are to be accepted as scientifically meaningful only if they can be strictly defined in terms of methods of empirical observations. Upon 
closer investigation, however, it turned out that theoretical concepts in science are not conceived and that scientists at work do not proceed according to this stringent criterion. In a remarkably self-critical analysis and revision, Herbert Feigl reinstituted the mind-brain-relation as a profound scientific problem of inquiry, ${ }^{3}$ and Carnap thoroughly revised his original criterion of theoretical concepts by allowing them to be introduced into the framework of scientific theories on much less stringent conditions: He postulated that theoretical concepts within a scientific theory make sense if their introduction has some consequences that can be empirically confirmed. This revised notion now is itself consistent with experience: it corresponds to the actual structure of science, in particular to that of quantum theory and other branches of physics. The corresponding "liberalization of empiricism", as Carnap has called it in his autobiography, was initiated in the late thirties, to be elaborated on for many years to follow. ${ }^{4}$ With the liberal criterion for meaningful theoretical concepts, however, it is accepted that they cannot be fully anchored in observational terms and procedures; metatheoretical, if not metaphysical, concepts are no longer strictly and unconditionally excluded on logical grounds. This implication leads to the question of whether and why the separation of scientific and religious concepts should be inevitable, as many people have thought.

Consider the relation between religious notions and the scope of human cognition. The theological notion that God created human beings in his image does at least qualitatively account for an empirical fact - namely, that human cognition is surprisingly well adapted to understanding nature. Its adaptation extends far beyond those capabilities of the brain that are easily understood, within the framework of evolutionary theory, in terms of increased "fitness" in social groups of hunters and gatherers. That the human mind can conceive laws of nature such as Einstein's formula $E=m c^{2}$ and that some, though not all, such constructs of the human mind are confirmed by observations of nature implies that there exists a hidden and abstract mathematical order of natural processes which is accessible to the human mind. It makes sense to search for explanations of this empirical, anthropological evidence in theoretical terms, if the liberalized concepts of such terms are accepted. One possibility appears to be conceptualization in religious terms - that is, considering human mental creativity as the image of God's actual creativity in creating the world and the laws of nature. This religious interpretation is not mainstream in the intellectual community but not because of stringent logical, epistemological, or empirical reasons.

In attempting to elucidate the deep paradigmatic changes in insights and attitudes in the middle of the twentieth century, one might resort to invented dialogues of the "Einstein meets Newton" type. The fundamental issues in relation to science and religion could be dramatized by an encounter between (1) a philosopher of science who discovers his concepts' openness to different metatheoretical interpretations, not excluding religious ones, while still maintaining a distinct personal dislike for religion, and (2) a mathematician who obtains amazing meta-mathematical re- 


\section{if $222 e^{-13.11 .40 .}$}

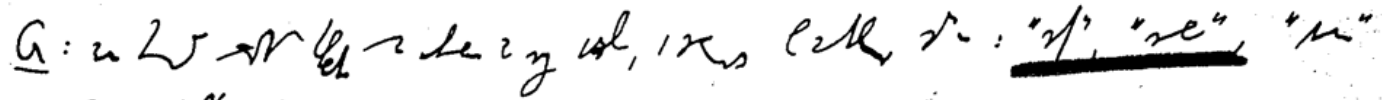
2. $\rightarrow$ orysi, rnmpen.

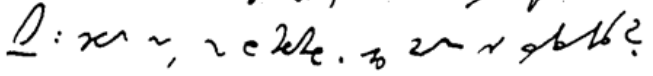

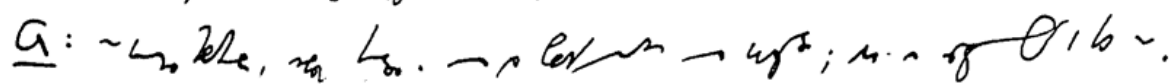

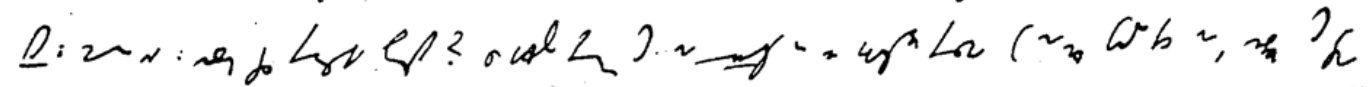

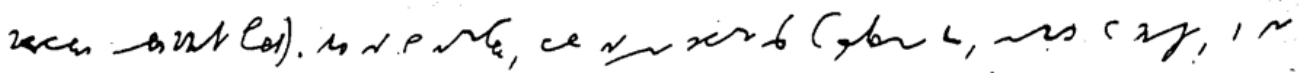

col z uforathe.

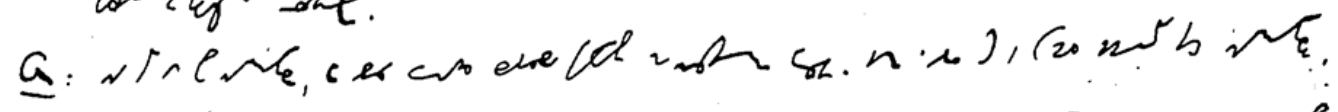

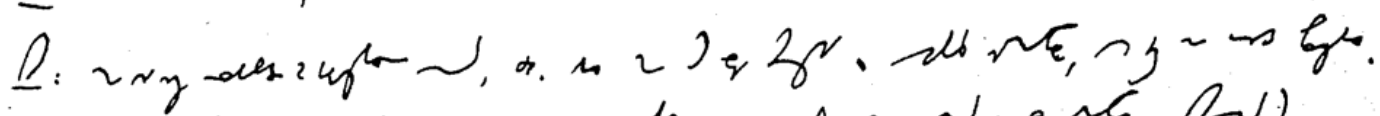

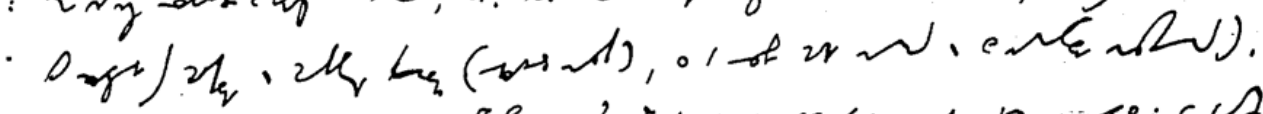

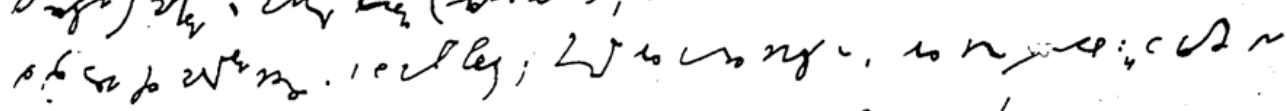

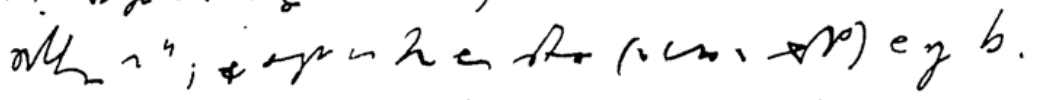

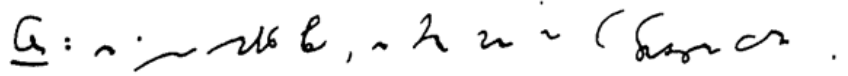

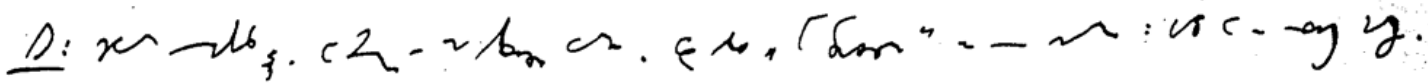

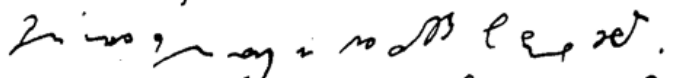

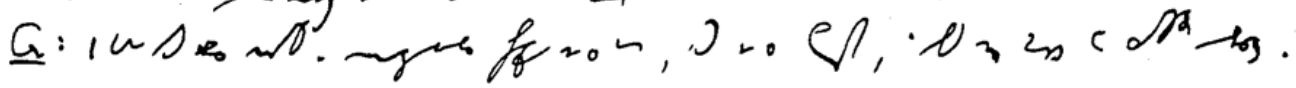

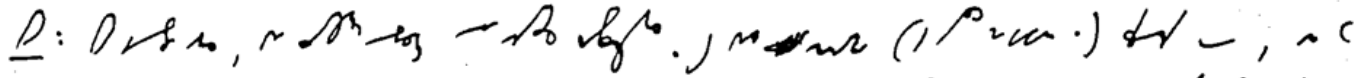

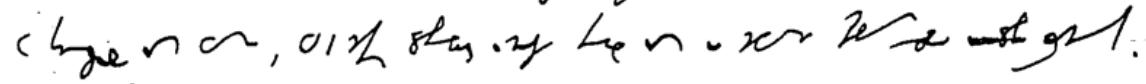

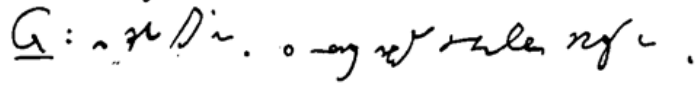

Figure 1: Carnap's shorthand note (system Stolze-Schrey) on his discussion with Gödel, 13 November, 1940. Source: Rudolf Carnap Archives, University of Pittsburgh Libraries, Special Collections Department, RC 102-43-06. Quoted with permission of the University of Pittsburgh, all rights reserved. For a transcript, see Appendix. 
sults that are open to a spectrum of interpretations, including religious ones that have a particular personal appeal to him. This dialogue does not have to be invented; it actually took place. On 13 November, 1940, Carnap and Gödel met on this very issue in Princeton, and Carnap took stenographic summarizing notes. The shorthand version is shown in figure 1, and a transcript (in German) with clarifications by B. Uhlemann in the Appendix. Translated into English, with my comments relating to the basic problems and developments mentioned in this article, Carnap's notes read as follows:

GÖDEL: One could establish an exact system of postulates employing concepts that are usually considered metaphysical: "God", "soul", "idea". If this is done accurately, there would be no objection.

CARNAP: Certainly not, if the system is just a calculus - or is it subject to interpretation?

GÖDEL: I am thinking not of a calculus, but of a theory. This theory has observable consequences, but the observed consequences do not exhaust the theory.

Gödel suggests a theory, or metatheory, encompassing theology. Such a theory would lead to consequences that can be assessed empirically, but the scope of the central theoretical concepts within such a theory would extend far beyond the objectively verifiable.

CARNAP: Do you mean in analogy to theoretical physics? Physical concepts cannot be translated into terms of observation (not only in quantum mechanics but already in respect to Maxwell's electromagnetic field). But they make sense nevertheless, because they allow for a certain type of interpretation by laws connecting the theoretical terms with observable features.

Carnap acknowledges that modern physics has a logical structure analogous to the one proposed by Gödel for theology: Physical theories contain concepts like the electron, the wave function, and the electromagnetic field, which allow for the derivation of observable and measurable facts, and yet these abstract concepts cannot be defined solely in terms of methods and results of observation; that is, on an exclusively empirical basis.

GÖDEL: You accept, as making sense, what would be unacceptable to other, less liberal positivists. With this acceptance, however, the theory I envisage makes sense as well.

Gödel gets to his main point: The notion: empirical consequences "yes", exhaustion of theoretical concepts by such consequences "no", is a liberalization of criteria for theoretical concepts of science originally proposed by Carnap and his friends. In this liberal spirit Carnap should admit that these criteria would apply to theological concepts just as they apply to physics. 
CARNAP: Yes, if your type of theory is connected with observable features; but even if it is logically correct and makes sense in empirical terms, I do not consider it productive from a scientific point of view. I distinguish between mythological and metaphysical theology (by the way, Neurath thinks so too, calling the mythological type magic and admitting that this makes sense). Yours would belong to the mythological type. In most cases they are wrong, but they could be improved. But I would insist that "we do not need such hypotheses", because our present science can explain everything and achieves this in a better and more exact way than a theological type of theory.

Carnap admits that Gödel's claim is correct, but only from a purely formal point of view; his notion on theoretical concepts in theology no longer contradicts notions of theoretical terms, say in physics, on strictly logical or epistemological grounds. But this formal consideration is insufficient, because it does not decide which conceptionalization is fruitful for the advance of knowledge and which is not. Science as we know it is so much better than any theology to be developed along the lines suggested by Gödel; we just do not need such hypothetical constructs.

GÖDEL: This question is an empirical one, and the answer cannot be known a priori.

CARNAP: Yes, this is indeed an empirical question that has no answer a priori. And yet it can be answered "from the outset", meaning it can be answered before we make the attempt. No scientist will consider an attempt in this direction to be worthwhile.

GÖDEL: In this respect I do not agree: Decisive progress in science - including physics - often depends on a change of direction.

CARNAP: But I maintain that the change of direction you propose would certainly be unproductive. This my assumption, which is of course not a proof, is supported by our knowledge of psychoanalysis and other fields of inquiry as to how the idea of God and all of theology and so on can be traced back to childhood experiences and beliefs.

GÖDEL: This I do not believe. I think the attempt I am suggesting should be made in any case.

This last part of the transcript describes how Gödel and Carnap supported different predictions about the fruitfulness and prospects of a theology conceptualized according to standards of theoretical terms applying to science. Gödel pointed out that paradigmatic changes of directions have often proved fruitful in the development of knowledge, and he insists that the attempt with respect to theology should be made. Carnap claims that no scientist would consider such an attempt worthwhile, in particular since we understand scientifically that religion is nothing but a psychological consequence of certain experiences in early childhood. 
In retrospect after half a century, we do not know very much more than Gödel and Carnap did around 1940; but it seems now, at least to me, that both Gödel and Carnap went too far in the statements supporting their respective views. On the one hand, the explanation of religion and theology in terms of early childhood psychology or other psychoanalytic or sociological evidence cannot exhaust the meaning of religion for human beings. On the other hand, a formal theology meeting the standards of stringency of, say, Gödel-type meta-mathematics is unlikely to be developed and may not even be desirable. The basic alternative for the interpretation of the body of knowledge, however, remains: With the liberalization of sensible criteria for theoretical concepts in science, metatheoretical options are opened with respect to the relation of the mental and the physical in general, and of science and religion in particular. These options include agnostic as well as religious notions, and the choice is a matter of intuition, personality, and judgment about what sustains a good way of living. Agnostic views such as Carnap's may claim advantages of down-to-earth realism, whereas religious options such as those favored by Gödel allow for metaphysical optimism in the understanding of nature and ourselves. In history both religious and agnostic lines of thought have developed intolerant as well as tolerant and liberal branches. It appears to be most important for human welfare that the liberal versions prevail in both religious and agnostic lines of thought. The insight that both are consistent with logical thinking and scientific facts may help, sustaining the prediction that agnostic and religious views will coexist in the long run.

\section{APPENDIX. TRANSCRIPT OF CARNAP'S SHORTHAND NOTES SHOWN IN FIGURE 1, REVISED BY B. UHLEMANN ${ }^{2}$}

Gespräch mit Gödel, 13.11.40

G.: Man könnte exaktes Postulatensystem aufstellen mit solchen Begriffe[n], die gewöhnlich für metaphysisch gehalten werden: "Gott", "Seele", "Ideen". Wenn das exakt gemacht wurde, wäre nichts dagegen einzuwenden.

Ich: Gewiss nicht, wenn als Kalkül. Oder meinen Sie interpretiert?

G.: Nicht blosser Kalkül, sondern Theorie. Aus ihr folgt einiges über Beobachtungen: aber das erschöpft die Theorie nicht.

Ich: Meinen Sie: Analog zur theoretischen Physik? Deren Begriffe können auch nicht übersetzt werden in Beobachtungsterme (nicht nur Quantentheorie nicht, sondern auch schon Maxwells elektromagnetisches Feld). Aber sie sind sinnvoll, weil sie eine gewisse Art von Interpretation haben, nämlich durch Gesetze, die diese Begriffe mit Beobachtbarem verknüpfen.

G.: Sie halten dies für sinnvoll, was andere weniger liberale Positivisten nicht anerkennen würden. Dann ist aber auch die von mir gemeinte Theorie sinnvoll.

Ich: Wenn sie solche Verbindungen mit Beobachtbarem enthält, ja. Aber wenn auch logisch korrekt und empirisch sinnvoll, so doch nicht wissenschaftlich fruchtbar. Ich unterscheide zwischen mythologischer und metaphysischer Theologie (übrigens Neurath auch, der die erste Magie nennt und als sinnvoll anerkennt). Ihre Art würde zur mythologischen gehören. Die sind meist falsch; könnten aber besser gemacht werden. Aber dann Einwand: "Wir brauchen diese Hypothesen nicht"; unsere jetzige Wissenschaft kann alles erklären (und besser und exakter) als solche Theorie.

\footnotetext{
${ }^{2}$ Source: Philosophical Archives, University of Konstanz
} 
G.: Das ist eine empirische Frage, das kann man nicht von vornherein wissen.

Ich: Gewiss empirisch. Wir können es nicht a priori wissen. Wohl aber "von vornherein" in dem Sinn: bevor wir den Versuch machen. Kein Wissenschaftler wird einen Versuch in dieser Richtung für lohnend halten.

G.: Da bin ich anderer Ansicht. Entscheidender Fortschritt in der Wissenschaft auch in der Physik, ist oft nur möglich durch Richtungsänderung.

Ich: Ich denke aber, diese Richtungs[ä]nderung wäre sicher unfruchtbar. Zu dieser Annahme (die natürlich nicht Beweis ist) trägt bei, dass wir durch Psychoanalyse usw. wissen, wie die Gottesvorstellung und ganze Theologie usw. auf gewisse Kindheitserlebnisse und Vorstellungen zurückgeht.

G.: Das glaube ich nicht. Der Versuch sollte jedenfalls gemacht werden.

\section{NOTES}

1. Gödel's life and his thoughts on metamathematics, philosophy, and to some extent, religion are the subject of the biography by H. Wang (1987).

2. Support for the assertion that the mind-brain relation may not be fully decodable by finite procedures appears in Gierer (1970), 40-53, and Gierer (1983).

3. Feigl`s recognition of the mind-body (or mind-brain) relation as a genuine scientific problem appears in The Mental and the Physical (1958).

4. Carnap summarizes these 'liberalized' ideas on theoretical concepts of science in his Philosophical Foundations of Physics (Carnap 1966, 223-246). He examines the development of these ideas in his "intellectual autobiography" (Carnap 1963, 1-84).

\section{REFERENCES}

Carnap, R. 1963. The Philosophy of R. Carnap, ed. P. A. Schilpp. La Salle,Ill.: Open Court. Carnap, R. 1966. Philosophical Foundations of Physics. New York: Basic Books.

Feigl, Herbert. 1958. The Mental and the Physical. Minnesote Studies II. Minneapolis: Univ. of Minnesota Press.

Gierer, A. 1970. "The Physical Foundation of Biology and the Psychophysic Problem". Ratio 12, 47-64.

Gierer, A. 1983.; "Relation between neurophysiological and mental states: Possible limits of decodability." Naturwissenschaften 70, 282-287.

Wang, H. 1987. Reflections on Kurt Gödel. Cambridge: MIT Press. 